\title{
An Analysis of Puns in The Big Bang Theory Based on Conceptual Blending Theory
}

\author{
Le Zhang \\ Shanxi Normal University, China
}

\begin{abstract}
Pun, as a rhetorical device, is widely employed in both written and oral language. It plays a key role in generating and carrying humorous effects. The former research of Puns is usually concentrated on its definitions, classifications, translation strategies, pragmatic functions and are mainly narrowed down to the scope of rhetoric, semantics and pragmatics. However, few scholars have studied puns from a cognitive perspective. Based on Conceptual Blending Theory, the author collects 100 puns from 40 episodes of the first two seasons of The Big Bang Theory as the sources of research subjects. According to the users, types and functions of puns and data analysis, this study has come to the following conclusions: (1) Among the many characters, Sheldon is the person who uses puns the most, which fully reflect his personality of arrogance and showing off. Meanwhile, contextual puns appeared the most in the sitcom, which indicates the sitcom has a close connection with daily life. (2) The mirror network model, single-scope network model and double-scope network model could be conducted to construct meaning, while the meaning construction of puns cannot be used through simplex network model. (3) Puns have four kinds of functions in The Big Bang Theory. The major functions of pun are humorous, followed by sarcastic, persuasive and aesthetic functions. This article is helpful to readers to understand the meaning of puns correctly, at the same time it can promote the further application of Conceptual Blending Theory.
\end{abstract}

Index Terms - Conceptual Blending Theory, puns, The Big Bang Theory

\section{INTRODUCTION}

The term pun is a form of word play that contains two or more meanings, by exploiting multiple meanings of words, or of similar-sounding words, for an intended rhetorical or humorous rhetorical effect. As a main figure of speech, pun is a widespread linguistic phenomenon in human life. It has been widely applied in diverse kinds of genres and registers, for instance, in the literature works, humorous stories, entertainment programs, jokes, advertisements and so on. A good pun contributes to making language subtle, implicit, humorous and vivid, thus it can attract readers' interests and make a profound impression on them. Since there is few studies of puns in a situation comedy by using Conceptual Blending Theory, the paper takes American sitcom The Big Bang Theory as an example, aiming at using the Conceptual Blending Theory to analyze the meaning construction of puns specifically.

This current paper attempts to answer the following questions:

(1) What are the distributions of puns in the sitcom The Big Bang Theory?

(2) How meanings of the puns are constructed based on the Conceptual Blending Theory?

(3) What are the functions of the puns in the sitcom The Big Bang Theory?

By studying the puns occur in people's daily activities, this paper helps English learners to understand English puns and American humor properly, thus improving their competence of using English and enhancing the efficiency and accuracy of their English study.

\section{LITERATURE REVIEW}

\section{A. Definition and Classifications of Pun}

The word "pun" is also called "paronomasia" in Latin. It firstly appeared in English can be traced back to John Dryden's work in 1662. Wang (2004) argues that puns can be found in old English and then be popular in the 14th century. Afterwards, puns are mainly used by famous writers such as Shelley and Dickens. Nowadays, Pun is an important figure of speech in English and plays an essential role in people's daily and literary life. It is widely employed in the jokes, advertisements, literature works, entertainment programs and so on at present.

According to Oxford English Dictionary, which defines pun as "The use of a word in such a way as to suggest two or more meanings or different associations, or the use of two or more words of the same or nearly the same sound with different meanings, so as to produce a humorous effect" (2002, p. 1143). Many researchers such as Wen (1995) and He (2004) have also defined pun. Based on them, pun mainly has three features: Firstly, the use of puns aims at expressing two different meanings in a specific context. Secondly, the audience can get both surface meaning and deep meaning of it by using puns. Thirdly, the use of pun can achieve special functions, for example, can produce humorous, sarcastic, persuasive and aesthetic effects.

Based on the study of puns, most scholars argue that pun can be mainly divided into two types, namely, homophonic 
and homographic puns. In the study, the author reads a large number of materials about the classification of puns and put them into effect in The Big Bang Theory. The current paper adopts the classification methods of Wen (1995) and Li (2000) as well as the frequency of puns' appearances in the sitcom, reclassifying puns into eight types. That is, asterismus pun, mimetic pun, antaladasis pun, homophonic pun, grammatical pun, paronomasia pun, sylleptic pun and contextual pun.

Asteismus pun aims to use the ambiguity of the same word or expression to attract people. It cause people a deliberate misunderstanding of the meaning and mostly appear in the form of dialogue.

Mimetic pun is created by using some proverbs, sayings and fixed phrases, etc. Writers often use the allomorph of certain word, which is a variant phonological representation of a morpheme, to form mimetic pun. Thus, the audience can be easily attracted and understand the mimetic pun properly.

Antaladasis pun means a word used two or more times in a language environment but every time they express different meanings. For instance,

Sheldon: No, not the Wesley Crushers. The Wesley Crushers.

The first "Wesley Crushers" here refers to people who like Wesley Crusher. The second "Wesley Crushers" is a blindingly clever play on words. It means the opponents of Wesley. It implies that they will be the crushers of Wesley.

Homophonic puns are words with the same pronunciation, but have different spellings and meanings. It makes a sentence embody two contents, and makes people feel its sense of humor. Take the following sentence for example:

Leonard: I hate my name. It has "nerd" in it.

In Leonard's name, "nard" has the same pronunciation of "nerd". He will be worried and depressed when called by his name, because the word "nerd" means "a foolish person" in English. Homophonic pun can make language filled with unique effect and wit.

Grammatical pun should obey grammatical skills, such as sentence structures, the application of ellipsis and part of speech, etc. The use of it makes the expression more amusing and interesting.

Paronomasia puns are formed by using two or more words with similar or nearly the same pronunciation, which generate double senses.

Sheldon: Singing is neither an appropriate vocation nor avocation for you.

From the sentence we can see that "vocation" and "avocation" has the similar pronunciation, but they express totally different meanings. Sheldon thinks that penny is apparently not suited to sing. So he uses the two words to make paronomasia pun to satirize Penny.

Sylleptic pun refers to one word occurs only one time with two or more meanings. It can easily express more information with fewer words and space.

Sheldon: This is my first day off in decades and I'm going to savor it

It is obviously that "savor" can be interpreted as "taste", but here it means "enjoy". The literal meaning of "savor" can remind people of the word "enjoy".

Through contextual pun, the audience can get the generated meaning by analyzing the original meaning of a word to deliver double meanings. Context is vital to interpret contextual pun and help people to get the optimal relevant meanings of puns.

\section{B. Conceptual Blending Theory}

Conceptual blending theory was first proposed by Fauconnier in1985. According to him, conceptual blending model involves four mental spaces, which are two input spaces, a blended space and a generic space. Fauconnier and Turner (1994) point out that frames and elements of two input spaces are selectively projected into the blended space, and via composition, elaboration and completion, both the emergent structure and emergent meaning are generated. In 2002 , Fauconnier and Turner hold that conceptual blending network could be divided into four groups, which are simple network, mirror network, single-scope network and double-scope network separately.

Among conceptual blending networks, simple network is the most fundamental pattern. In one input space, there exists a blank and abstract framework and some regulations, however, the other has no framework. It just has some elements to fill in the abstract frame. The two input spaces are connected after mapping of rule and value.

In mirror network, the two input spaces both provide frameworks. They are the same but elements of them are different. The two mental inputs spaces, blended space and generic space share only one frame in this model.

The two input spaces have different frameworks in Single-scope Network. Only one input space will be chosen to the blended space and carry on running in the blending space. The emergent structure is generated through the process of composition, completion and elaboration.

In the double-scope network, the two input spaces have different frameworks. But different from single-scope framework, the two input spaces of double-scope framework both project into the blending space. The blending network is the mostly used by people.

\section{An Analysis of Puns in The Big BANG Theory Based on Conceptual Blending Theory}

\section{A. The Distributions of Puns in The Big Bang Theory}

The present paper collects 100 puns from 40 episodes in the sitcom The Big Bang Theory from the first two seasons 
as the research materials. The author watched the sitcom and took down the puns appeared in the daily conversations. The study is taken from three aspects: users of puns, the types of pun, functions generated by puns. Finally, the author adopts tables to show the research results.

TABLE 1

NUMBERS OF PUNS USED BY CHARACTERS

\begin{tabular}{|l|l|}
\hline Names of characters & Numbers of puns(totally 100) \\
\hline Sheldon & 39 \\
\hline Leonard & 22 \\
\hline Penny & 15 \\
\hline Raj & 11 \\
\hline Howard & 7 \\
\hline Amy & 4 \\
\hline Bernadette & 2 \\
\hline
\end{tabular}

From the Table 1, we can see that Sheldon is the most active person and the main character in this sitcom. The numbers of puns he used are 39, which can reflect his characteristics of showing off and arrogance.

TABLE 2

NUMBERS OF DIFFERENT TYPES OF PUNS

\begin{tabular}{|l|l|}
\multicolumn{2}{|c|}{ NUMBERS OF DIFFERENT TYPES OF PUNS } \\
\hline Types of puns & Numbers of puns(totally 100) \\
\hline Contextual pun & 56 \\
\hline Sylleptic pun & 14 \\
\hline Paronomasia pun & 11 \\
\hline Grammatical pun & 7 \\
\hline Homophonic pun & 5 \\
\hline Antalaclasis pun & 4 \\
\hline Mimetic pun & 2 \\
\hline Aterismus pun & 1 \\
\hline
\end{tabular}

It is not hard to see from Table 2 that contextual puns appear the most in the sitcom, which reflects the characters often speak by combining with environments situations and indicates that the series has a closely connection with daily life. On the other hand, asterismus puns, mimetic puns, antalaclasis puns, homophonic puns and grammatical puns are so less.

TABLE 3

DISTRIBUTION OF DIFFERENT FUNCTIONS OF PUNS

\begin{tabular}{|l|l|}
\multicolumn{2}{|c|}{ DISTRIBUTION OF DIFFERENT FUNCTIONS OF PUNS } \\
\hline Different Functions of Puns & Numbers of puns(totally 100) \\
\hline Humorous function & 45 \\
\hline Humorous and sarcastic function & 31 \\
\hline Sarcastic function & 13 \\
\hline Persuasive function & 9 \\
\hline Aesthetic function & 2 \\
\hline
\end{tabular}

According to Table 3, it can come to the conclusion that the humorous function is the most important one in the series. Sarcastic, persuasive and aesthetic puns are relatively less in number. Humorous and sarcastic functions' using interprets that people are not only humorous, but sarcastic, which indicates there are always contradictions and misunderstandings between people.

After this study, people will have deeper understanding of puns and their significance. At the same time American sitcom, American people and American culture will be understood more accurately.

\section{B. Meaning Construction of Puns in Conceptual Blending Theory}

\section{Meaning Construction of Puns in Mirror Network}

The two input spaces both provide frameworks in the Mirror Network. They are the same but elements of them are different. For instance,

Sheldon's mother: I thought it was our Indians that had the occasional alcohol problem.

Leonard: We don't say that, either. I'll make you a list.

Sheldon's mother: Oh, that would be mighty white of you.

Rajesh is an Indian boy who has a psychological disorder in speaking with females. One day he feels lonely and drank. When Leonard and Sheldon's mother come back from dinner, they are surprised by Rajesh. Sheldon's mother is ethnocentric and said above words to Leonard. Leonard held that it is kind of racial discrimination and in order not to cause unnecessary embarrassment he tells Sheldon's mother not to say so. However, Sheldon's mother is unwilling to accept it and says the above sentences.

After reading the dialogue, we know that the word "white" acts as the hinge of pun. It has two meanings: "the color of skin" and "the honesty of nature". These two meanings provide two frames separately: "someone is with white skin" in input space 1 and "someone is honest" in input space 2. Based on Sheldon's mother's reply, it can conclude that she 
wants to satire Leonard. It's easy for the audience to come to mind the same frame: "someone has some features". The emergent structure is formed after the process of composition, completion and elaboration. Then the emergent meaning is generated: "a white man that is also very honest". That is the process of meaning construction of pun "white" with the help of mirror network in Conceptual Integration Theory.

\section{Meaning Construction of Puns in Single-scope Network}

In Single-scope Network, the two input spaces have different frameworks. Only one of them will be projected to blended space and continue to run in the blending space. After composition, completion and elaboration, the emergent structure is generated. Take the following dialogue as an example,

Howard: Okay, okay, tell you what. I am willing to bet anything that's an ordinary field cricket.

Sheldon: I can't take your money.

Howard: What's the matter, you chicken?

In this conversation, Howard would like to have a bet with Sheldon about the types of a cricket, but Sheldon are reluctant to bet with him. So Howard uses a conceptual pun "chicken" to deride Sheldon. It constructs two contexts: "chicken eat crickets" and "a coward man couldn't make a decision", and different input spaces frames are generated by double contexts provided. They match with each other. Based on the two inputs spaces, the generic space is produced "the relation between two substances". Under the guidance of generic space, the two input spaces' elements are projected into the blended space selectively and the framework of input space 2 is projected into the blended space, so it belongs to the single-scope network.

Through composition, completion and elaboration, the emergent structure "chicken fears crickets" is generated within the single-scope blended space, which means Howard ridicules Sheldon and he believes "Sheldon is like coward chicken which fears crickets".

\section{Meaning Construction of Puns in Double-Scope Network}

In the double-scope network, the two input spaces have different frameworks. But different from single-scope framework, the two input spaces of double-scope framework both project into the blending space. For example,

Howard: Hi! It's hot here, must be summer!

From the sentence, we can know that there are two different frames. One is "It's hot in summer", the other is "the person named Summer has a sexy figure". As we know, the word "summer" contains two meanings: "season" and "a person's name". Meanwhile, the word "hot" stimulates the double contexts of the pun. Then, the frames and elements of these two input spaces are selectively projected into the blended space. After composition, completion and elaboration, the emergent structure is generated: "something have some properties".

According to the analysis, it can be concluded that there are no puns analyzed in simple conceptual blending network. The reason is the puns are normally "playing on words" of the two meanings of the same expression and also the double contexts, which are created by the double meanings. There must be two frames for two input spaces. But the other three models (Mirror network model, Single-scope network model, Double scope network model) all could be used construct meaning.

\section{The Functions of Puns In The Big BANG THEORY}

\section{A. Humorous and Sarcastic Function}

Pun has the unique features of killing two birds with one stone and selling the dummy. It has already been people's best choice to achieve the function of humor or satire. In everyday conversation, the meaning of a word relies on its contexts. Unlike jokes, humor and satire are reflection of intelligence and ridiculous forms appealing to reason and rich in meanings. Take this sentence for example,

Howard: Hi! It's hot here, must be summer!

In this sentence, the main function of contextual pun "summer" is humor. Some audience finds it a bit difficult to understand while watching the sitcom, however, on second thoughts, they assure themselves that the humorous function of the pun is used to achieve comic effect. The famous actress is named "Summer". Here Howard would like to use hot and summer to describe the actress is so attractive and sexy. He employs adjective "hot" and noun "summer" which are used to modify weather to describe a person, so the humorous and sarcastic function is achieved.

\section{B. Aesthetic Function}

The beauty of puns lies in that it can incarnate the emotion of language, give readers moral enjoyment and spiritual pleasure, and voice the inner world of the characters. There would be conflicts between elements within the emergent structure and the blended space. Under the guidance of world experiences and related knowledge, conflicts could be solved. For instance,

Howard: Starting tomorrow, I am turning over a new leaf.

The emergent structure of this sentence is "Howard will turn a new page". On the surface, it is logically nonsense, because there is no book. In view of Howard's purpose for saying the sentence, he wants to tell Bernadette about his decision. Here, using a leaf from a tree as the page of a book, it can easily make people feel the beauty of this sentence. Howard indicates to turn over a page that refers to say goodbye to the past. The audience realizes that Howard is using sylleptic pun to express his decision to Bernadette, in order to restore the good relationships with Bernadette and thus 
people could feel the aesthetic function of this pun.

\section{Persuasive Function}

There are also some puns embody persuasive functions in The Big Bang Theory. People sometimes do not use direct sentences to express their aims. Instead, to achieve a persuasive function, they use puns to express their intention. It can make the language more euphemistic, more meaningful, and more suitable. For example,

Sheldon: Be a lamb and open it for me.

Leonard: Why? What's the problem?

In this dialogue, "lamb" is a contextual pun, which has two meanings. One is "a kind of animal" and the other is "a good man". There exists a conflict that a lamb can't open a door. With the help of meaning construction of conceptual blending theory and related knowledge and world experiences, people can take its context into consideration. Sheldon doesn't want to come to work. So he uses a machine that is controlled by him to work with Leonard. The machine can not open the door, so Sheldon aims at letting Leonard open the door for him. He uses "lamb" to describe Leonard as a good man who is very warm-hearted and ardent, so as to persuade him to open the door for him. So the persuasive function is easily achieved.

\section{CONClusions}

In this paper, the author takes a research on puns from the perspective of Conceptual Blending Theory in American sitcom The Big Bang Theory. The analysis of those puns has been taken from three aspects: distribution of puns in The Big Bang Theory, meaning construction of puns using four frameworks models of Conceptual Blending Theory, the functions of puns in The Big Bang Theory. Different from the previous research, this paper has reclassified puns into eight kinds. And then the author puts forward the study results by figures and tables. Except for the humorous function, the author also discovers sarcastic, persuasive and aesthetic functions of puns.

\section{SUGGestions FOR THE FURTHER STUdY}

There are some limitations in the study. The first one is that the current research mainly talks about the analysis of puns' sentence talks in people's daily conversation, so other forms of puns such as short sketches could be studied in the future. The second one lies in the 100 puns are mainly collected from 40 episodes from the first two seasons of The Big Bang Theory. It also has limitations, because the number of puns is not adequate enough to support the conclusion of this research.

Conceptual Blending Theory still needs to be explored with more attention and research. In the future, the four frameworks of Conceptual Blending should be broadened to explain more complicated words, phrases and sentences of puns. The research focus could be shifted to some typical language forms, such as talk shows, short sketches and so on. At the same time, there would be a more suitable and proper way to classify puns. It also can adopt other theories to deal with the meaning construction of puns, like Mimetics, Relevance Theory and Relevance Theory, which can be employed to make an easily comprehensive, convincing explanation of pun's meaning construction.

To sum up, the author hopes that this research can be a reference used for the future study and provide some new ideas on the further studies of Conceptual Blending Theory and puns.

\section{REFERENCES}

[1] Fauconnier, G. (1985). Mental Spaces: Aspects of Meaning Construction in Natural Language. Cambridge: Cambridge University Press.

[2] Fauconnier, Gilles. (1994). Mental Spaces: Aspects of Meaning Construction in Natural Language. Cambridge: Cambridge University Press.

[3] Fauconnier, Gilles \& Turner, Mark. (1995). Conceptual Integration and Formal Expression. In Mark Johnson (ed.), Journal of Metaphor and Symbolic Activity. 3, 183-203.

[4] Fauconnier, G \& M. Turner. (2002). The Way We Think. New York: Basic Books.

[5] Li Xinhua. (2000). Rhetorical Theory. Shanghai: Foreign Language Education Press.

[6] Wang Zhiwei. (2004). A Review of the Traditional English Puns. Journal of Shangqiu Normal University. 4, 164-166.

[7] Wen Jun. (1995). English Writing Rhetoric. Chongqing: Chongqing University Press.

Le Zhang was born in Linfen, China in 1994. She is studying for a master's degree in linguistics from Shanxi Normal University, China.

She is currently a postgraduate in the College of Foreign Languages, Shanxi Normal University, Linfen, China. Her research interests include Foreign Language Teaching and Learning and Pragmatics.

Le Zhang is now an external teacher of the College of communication in Shanxi Normal University. 